\title{
Optimization of cyclodextrin glycosyltransferase production by response surface methodology approach.
}

\begin{abstract}
The aim of the study was to optimized cyclodextrin glycosyltransferase (CGTase) production using local isolated strain MK6 which was identified as Bacillus sp. Optimum activity obtained at temperature of $70{ }^{\circ} \mathrm{C}$ and the enzyme shows a wide range of $\mathrm{pH}$ stability ranging from 4-10 when stored at $4{ }^{\circ} \mathrm{C}$ for $24 \mathrm{~h}$ and temperature stability ranging from $30-80{ }^{\circ} \mathrm{C}$ at 1 $\mathrm{h}$ incubation period. The CGTase activity was even maintained at $0.4 \mathrm{U} \mathrm{mL}-1$ at $90{ }^{\circ} \mathrm{C}$ for 40 min incubation. Prior to optimization of CGTase production, selection for the best carbon source through detection using modified phenolphthalein method containing different types of starch were performed. Sago starch gave significant result and was used for further optimization using statistical analysis namely Response Surface Methodology (RSM) approach. The optimal calculated values were 3.34\% sago starch, initial $\mathrm{pH}$ of 10.15 and agitation speed of $187 \mathrm{rpm}$; with predicted activity of $2.07 \mathrm{U} \mathrm{mL}-1$ of CGTase. These predicted optimal parameters were confirmed in the laboratory and the final CGTase activity obtained was very close to the predicted value of $2.56 \mathrm{U} \mathrm{mL}-1$.
\end{abstract}

Keyword: Cyclodextrin glycosyltransferase (CGTase); Optimisation; Response Surface Methodology (RSM). 